\title{
Estereótipos de Gênero em Adolescentes: Uma Análise da Influência Escolar sobre a Formação, Manutenção e Mudanças dos Estereótipos
}

\author{
Luciana Lopes de Oliveira \\ Dalva Cristina Aparecida de Jesus \\ Maria Aparecida de Lima Arruda \\ Maria Celestina da Cunha \\ Raquel Mara Araújo \\ Universidade Presidente Antônio Carlos
}

\begin{abstract}
RESUMO
Esta pesquisa teve como objetivo investigar estereótipos de gênero entre adolescentes alunos de uma escola leiga e outra confessional, buscando identificar possíveis diferenças que a orientação da escola pudesse exercer em seus alunos na formação, manutenção e mudança dos estereótipos. A proposta deste trabalho possibilitou traçar um perfil da percepção estereotipada dos adolescentes sobre seus pares femininos e masculinos em três níveis de análises: autoestereótipos, heteroestereótipos e metapercepção. Para isso, foram utilizadas escalas tipo Likert de cinco pontos e os dados obtidos foram analisados estatisticamente utilizando-se estatística descritiva e ANOVA. As análises indicaram que as mulheres são preferencialmente caracterizadas por traços coletivistas. Contudo, o número de atributos individualistas que são aplicados a elas é bastante significativo, diferente da caracterização masculina que é fortemente marcada por atributos individualistas e carece de atributos coletivistas. As atribuições são mais intensas entre os alunos da escola confessional, o que sugere que esse grupo tende a utilizar mais os estereótipos existindo uma tendência marcante em favorecer o próprio grupo nas atribuições. Os dados indicam que as mulheres são mais estereotipadas que os homens tanto no número de atributos usados na caracterização quanto na intensidade com que esses são atribuídos.
\end{abstract}

Palavras-chave: adolescência; estereótipos; gênero; educação escolar.

\section{ABSTRACT \\ Gender Stereotypes in Adolescents: an Analysis of the School Influence on the Formation, Maintenance and Changes of Stereotypes}

This research aimed at investigating gender stereotypes among adolescent students of two schools one religious and the other non-religious - trying to identify possible differences that the school orientation could exert on its students in the formation, maintenance and change of stereotypes. This work proposal made it possible to trace a profile of the adolescents' stereotyped perception on their male and female peers in three analysis levels, auto-stereotypes, hetero-stereotypes and meta-perception. For this purpose, five-point Likert scales were utilized and the data obtained were analyzed statistically utilizing descriptive statistics and ANOVA. The analyses indicated that women are mainly characterized by collective traces. However, the number of individualistic attributes which are applied to them is quite significant, differently from the male characterization which is strongly marked by individualistic attributes and lacks of collective ones. The attributions are more intense among the students of religious school, what suggests that this group tends to utilize more often the stereotypes and that there is a marked tendency towards the ingroup in the attributions. The data indicate that women are more stereotyped than men in the number of attributes used in the characterization as well as in the intensity with which they are attributed.

Keywords: adolescence; stereotypes; gender; school education.

O estudo sobre estereótipos e temas correlatos como comportamento e atitude sexual (Costa, \& Nunes, 2002; D’Amorim, 1997; Fonseca, 2002), papéis sexuais
(Desouza, Baldwin \& Rosa, 2000), comportamento e atitudes raciais, escolhas profissionais, percepção de liderança, colocação profissional, profecias autorreali- 
zadoras (Lima \& Pereira, 2004), autoestima e autoconceito (Greenwald \& cols., 2002), entre outros, vem sendo objeto de investigação por parte de muitos pesquisadores. Desde o primeiro estudo realizado pelo jornalista norte americano Walter Lippmann em 1922, este de cunho axiológico, os psicólogos vêm se dedicando a entender mais sobre esse fenômeno. Os estudos de Lippmann contrariavam o pensamento tradicional de que somente após a observação do mundo as pessoas tirariam suas conclusões. Esse trabalho surgere, então, que as pessoas expressam seu ponto de vista sobre o mundo retratando-o apenas parcialmente. A cultura seria responsável por influenciar a visão sobre o mundo, uma vez que ela oferece, às pessoas, um sistema de crenças, valores, regras e comportamentos, influenciando as respostas, destas, às suas experiências. Essa tendência se justificaria pela existência do princípio do menor esforço, a partir do qual, as opiniões seriam previamente estabelecidas com base nos códigos oferecidos pela cultura e acionadas quando necessárias facilitando, assim, o processamento de informação do homem (Pereira, 2002).

A noção de estereótipo como consenso social sobre características de determinado grupo foi defendida pelo psicólogo britânico Henri Tajfel (1982). Na perspectiva do pesquisador, os estereótipos passam a ser entendidos como crenças compartilhadas sobre um grupo social. Hertel e Kerr (2001) argumentam que alguns autores consideram os estereótipos como sendo sociais uma vez que respondem de acordo com características típicas de grupos sociais salientes. Eles defendem que algumas teorias, como a Teoria da Aprendizagem Social, e alguns métodos de pesquisa, como as listas de adjetivos, refletiriam a visão de estereótipos sociais como "atitudes públicas", "representações coletivas" ou "compreensão compartilhada da realidade social".

Segundo Krüger (1986), de modo geral, poderíamos definir estereótipos como um conjunto de atribuições generalizadas feitas a um grupo humano. De acordo com Pereira (2002), uma definição mais completa foi oferecida por Hamilton e Troiler a partir do conceito no qual se articulam processos psicológicos e sociais. Nela os estereótipos são entendidos como estruturas cognitivas que contêm conhecimentos, crenças e expectativas do percebedor sobre um grupo social.

Os processos cognitivos são fundamentais na formação e manutenção dos estereótipos - Lippman já os reconhecia como elementos mentais. O psicólogo norte americano Gordon Allport foi um dos primeiros a estudar o processo de categorização, afirmando que as pessoas tendem a categorizar tudo que percebem. Em 1935, na revisão do Handbook of Social Psichology, Allport começou a esboçar sua teoria sobre os estereótipos, que seria apresentada mais tarde no seu livro The Nature of Prejudice, publicado em 1954. Neste livro, Allport apontou tanto os aspectos cognitivos quanto a função defensiva dos estereótipos quando usados como justificativa para a nossa indisposição em relação aos membros de grupos externos. Também nele, o autor procurou estabelecer um vínculo entre estereótipos, preconceito e processo de categorização. A categorização teria como características principais a formação de classes e categorias responsáveis por facilitar a atividade humana. De acordo com essa visão, as pessoas categorizam naturalmente qualquer objeto do mundo e esta categorização ajudaria a manter o mundo em ordem (Allport, 1988).

A partir dessa teoria, Tajfel (1982) estudou as estratégias utilizadas pelas pessoas para diferenciar o próprio grupo (ingroup) do grupo externo (outgroup). Reafirmou o postulado de Allport de que os estereótipos surgem a partir do processo de categorização e que sua função é introduzir simplicidade e ordem onde existe complexidade. Os estereótipos, também teriam a função de ajudar as pessoas a transformar diferenças não muito claras entre grupos em diferenças mais nítidas, ou mesmo criar diferenças onde não exista nenhuma. Segundo Tajfel (1982), haveria uma tendência a favorecer o próprio grupo, percebendo-o de forma mais positiva e heterogênea. Por outro lado, também haveria uma tendência das pessoas ressaltarem as características negativas do grupo externo e rejeitá-lo, ou seja, as pessoas generalizariam com mais frequência e facilidade os atributos dos membros do grupo externo, sendo esse o princípio norteador do desenvolvimento da Teoria da Identidade Social. De acordo com Hertel e Kerr (2001), uma das suposições sobre esta tendência refere-se a processos motivacionais que levariam as pessoas a realçar positivamente seu próprio grupo como forma de realçar sua autoestima social e de proteger a identidade grupal.

Assim, estereótipos e preconceitos estão relacionados à categorização social. A categorização ocorre quando, em vez de se pensar sobre uma pessoa como um indivíduo único, pensa-se nela como membro de um grupo, e, ao se categorizar alguém, rapidamente ativam-se pensamentos e sentimentos sobre essa categoria. Esses pensamentos ativados seriam as estruturas cognitivas, às quais se denominam estereótipos 
que, por sua vez, são os componentes cognitivos que, junto aos sentimentos, formam os preconceitos.

Esse trabalho teve como objetivo contribuir para o desenvolvimento do estudo sobre os estereótipos no que se refere ao processo de socialização dos adolescentes. Pretendeu-se, através deste, identificar os conteúdos dos estereótipos de gênero em adolescentes; identificar os autoestereótipos-estereótipos e heteroestereótipos de gênero; identificar a metapercepção, ou seja, como os sujeitos se julgam percebidos pelo sexo oposto assim como, investigar possíveis influências da orientação da escola (religiosa ou leiga) na manifestação dos estereótipos de gênero em adolescentes.

\section{MÉTODO}

\section{Participantes}

Participaram da pesquisa 239 adolescentes do sexo masculino e feminino com idades entre 14 e 19 anos. Esses adolescentes eram alunos do ensino médio de dois colégios localizados no interior de Minas Gerais - um colégio identificado como sendo de orientação confessional, e o outro como um colégio leigo. Os participantes da pesquisa foram selecionados através de um sorteio realizado a partir da lista de alunos matriculados, oferecida pela direção de cada colégio. Para este sorteio, utilizou-se uma escala de números aleatórios. Foram sorteados 240 adolescentes, sendo metade homens e metade mulheres, 120 eram alunos do colégio confessional e 119 alunos do colégio leigo. Esse número de participantes foi dividido entre as três séries do ensino médio, ou seja, foi realizada uma amostra estratificada garantindo a participação semelhante, em números, de todas as séries.

\section{Instrumentos}

$\mathrm{Na}$ coleta dos dados, foram utilizadas três escalas tipo Likert de cinco pontos variando de 1 (discordo totalmente) a 5 (concordo totalmente). Cada uma das escalas foi formada por proposições com relação a características destinadas aos adolescentes masculinos e femininos (exemplo: "As adolescentes são inteligentes"; "Os adolescentes são inteligentes"), de forma que todos os adjetivos fossem aplicados para ambos os grupos. Esses adjetivos (21 no total) foram coletados junto a adolescentes da cidade.

As três escalas usadas na pesquisa tinham a mesma estrutura; a distinção estava no foco de avaliação que o adolescente iria realizar com relação ao gênero masculino e feminino (heteroestereótipos, autoestereótipos e metapercepção). Todos os participantes da pesquisa responderam as três escalas.

\section{Procedimentos}

Após a seleção dos participantes, foi realizada uma reunião de esclarecimento sobre a pesquisa com os mesmos em cada um dos colégios e, nesta, foi entregue o Termo de Consentimento Livre e Esclarecido. A coleta de dados foi realizada com grupos pequenos de participantes em uma sala disponibilizada pela direção dos colégios. Os alunos selecionados em cada turma eram chamados a comparecer na sala e a responder as escalas. As escalas eram apresentadas uma de cada vez, após o preenchimento da fornecida anteriormente. A ordem de apresentação das escalas era mudada a cada grupo para evitar um possível efeito de fadiga.

\section{Análise dos dados}

Os dados coletados foram analisados estatisticamente. Utilizaram-se medidas descritivas (média e desvio padrão das respostas) para identificação dos auto e heteroestereótipos e da metapercepção. As medidas inferenciais sobre a interação entre as variáveis escola e sexo foram realizadas através da ANOVA para o planejamento em plano fatorial.

\section{RESULTADOS}

O critério estabelecido para definir os estereótipos dos adolescentes femininos e masculinos foram aqueles adjetivos que obtiveram médias superiores a 3,50. Assim, o autoestereótipo das meninas foi composto pelos adjetivos: vaidosas (4,71), sensíveis $(4,43)$, companheiras $(4,40)$, românticas $(4,35)$, persistentes $(4,30)$, delicadas $(4,26)$, inteligentes $(4,22)$, legais $(4,18)$, organizadas $(4,05)$, bonitas $(4,04)$, responsáveis $(3,92)$, autoritárias $(3,87)$, farristas $(3,84)$, estudiosas $(3,80)$, sinceras $(3,62)$, metidas $(3,61)$.

O heteroestereótipo foi composto pelos adjetivos: vaidosas $(4,61)$, sensíveis $(4,40)$, delicadas $(4,33)$, organizadas $(4,25)$, bonitas $(4,22)$, legais $(4,09)$, farristas $(4,00)$, estudiosas $(3,95)$, convencidas $(3,91)$, românticas $(3,90)$, companheiras $(3,89)$, metidas $(3,89)$, inteligentes $(3,84)$, responsáveis $(3,80)$, autoritárias $(3,62)$, persistentes $(3,45)$.

A metapercepção foi composta pelos adjetivos: vaidosas $(4,80)$, sensíveis $(4,66)$, românticas $(4,40)$, metidas $(4,30)$, convencidas $(4,27)$, autoritárias $(4,18)$, organizadas $(4,17)$, companheiras $(4,10)$, estudiosas $(4,04)$, delicadas $(4,03)$, bonitas $(3,95)$, responsáveis $(3,92)$, persistentes $(3,87)$, legais $(3,83)$, farristas $(3,77)$.

Esses dados possibilitam algumas observações sobre os estereótipos femininos como o fato das meninas terem um número alto de atribuições nos três níveis 
estudados. Dos 21 adjetivos utilizados, elas obtiveram de 15 a 16 adjetivos com nível de atribuição considerável. Um dado interessante é o fato de o adjetivo "vaidosas" ter sido o primeiro em média de atribuição nos três níveis estudados indicando uma semelhança entre autoestereótipos, heteroestereótipos e metapercepção no que se refere à dimensão de cuidados com a aparência física. Interessante notar ainda que os resultados sobre esse atributo revelam que as adolescentes acreditam serem vistas como vaidosas pelos meninos numa intensidade maior que a revelada por eles e maior que a forma pela qual elas próprias as vêem. Esse adjetivo tradicionalmente é considerado um atributo negativo que demonstra futilidade. Contudo, na cultura brasileira, esse termo tem sido usado de forma ambígua, podendo indicar uma pessoa que se preocupa em apresentar-se bem, mas não necessariamente que se ocupe única e exclusivamente da aparência. Assim, fica difícil, hoje, admitirmos um aspecto absolutamente negativo para esse termo.

De modo geral, é possível notar uma concordância entre os atributos apresentados nos três níveis de análise estudados. Contudo, algumas diferenças podem ser apontadas como o fato de que as meninas se veem como "sinceras", atributo que não corresponde à visão dos participantes do sexo masculino sobre elas (heteroestereótipo) e nem da metapercepção (como elas acreditam serem percebidas por eles). Outro ponto de discordância está relacionado ao adjetivo "convencidas" que não aparece no autoestereótipo, mas é valorizado no heteroestereótipo e na metapercepção, sendo que o valor assumido na metapercepção é mais intenso que o valor assumido no heteroestereótipo. Isso sugere que elas acreditam serem percebidas como mais convencidas pelos meninos do que realmente o são. O adjetivo "inteligente" aparece no auto e no heteroestereótipo, mas não aparece na metapercepção, o que indica que elas se veem como "inteligentes" $\mathrm{e}$ que os meninos também as avaliam como tal. Elas, por outro lado, não acreditam serem vistas dessa forma por eles. Com relação a esse adjetivo, podemos dizer que apesar dele aparecer tanto no auto quanto no heteroestereótipo, é no autoestereótipo que esse adjetivo aparece com mais intensidade.

As médias obtidas para os meninos caracterizando o autoestereótipo deles são compostas pelos adjetivos farristas $(4,60)$, legais $(4,23)$, persistentes $(4,18)$, companheiros $(4,06)$, autoritários $(3,78)$, vaidosos $(3,73)$, agressivos $(3,70)$, inconsequentes $(3,58)$.

O heteroestereótipo é composto pelos adjetivos farristas $(4,65)$, convencidos $(4,19)$, autoritários $(4,08)$, legais $(3,99)$, persistentes $(3,92)$, vaidosos $(3,82)$, companheiros $(3,81)$, inconsequentes $(3,80)$, bonitos $(3,76)$, metidos $(3,74)$, arrogantes $(3,70)$, agressivos $(3,67)$, inteligentes $(3,63)$.

A metapercepção é composta pelos adjetivos farristas $(4,58)$, persistentes $(4,07)$, legais $(3,98)$, convencidos $(3,93)$, inconsequentes $(3,78)$, agressivos $(3,76)$, autoritários $(3,76)$, companheiros $(3,72)$, bonitos $(3,67)$, metidos $(3,60)$, inteligentes $(3,53)$.

Esses dados permitem observar que a atribuição de características aos membros do grupo masculino tem uma intensidade menor em comparação com as atribuições feitas aos membros do grupo feminino. Este resultado foi verificado em pesquisa realizada por Oliveira (2004). Aqui, o menor número de adjetivos foi encontrado nas atribuições do autoestereótipo. Existe uma correspondência entre os atributos apresentados nos três níveis de análise, com destaque para o adjetivo "farristas", o qual aparece com a maior média em todos os níveis (como ocorreu com o adjetivo vaidosas na caracterização das meninas), e para o adjetivo "vaidosos" que ocorre no autoestereótipo e no heteroestereótipo, mas não ocorre na metapercepção. Ou seja, os meninos se veem como vaidosos, são vistos como vaidosos pelas meninas, mas não esperam que sejam percebidos, assim, por elas. Existe uma correspondência forte entre o que as adolescentes pensam sobre os meninos (heteroestereótipo) e entre o que eles acreditam que elas pensam deles (metapercepção), com exceção dos adjetivos "vaidosos" e "arrogantes", que aparecem no heteroestereótipo e não aparecem na metapercepção e para o adjetivo "inteligentes" que aparece na metapercepção e não parecem nos outros níveis avaliados. Sobre essa atribuição, é possível avaliar que apesar dos meninos não se perceberem como "inteligentes" e nem serem vistos como tal, eles acreditam que as meninas os identificam assim. Os adjetivos "bonitos", "convencidos" e "metidos" são atributos que ocorrem no heteroestereótipo e na metapercepção, mas não ocorrem no autoestereótipo. Isso indica que os meninos não se veem como tal, mas acreditam que são vistos assim, e as adolescentes confirmam a crença deles quando atribuem esses adjetivos ao grupo masculino.

Para verificar o nível de variação das médias nas respostas dos participantes e analisar as atribuições feitas ao próprio grupo e ao grupo externo, foi utilizada a ANOVA para medidas repetidas, considerando a escola e o sexo como variáveis independentes interparticipantes. Para analisar a metapercepção, foi utilizada a ANOVA univariada. Para proceder à análise os adjetivos, foram agrupados em blocos de relações que compreendem atributos instrumentais e atributos 
expressivos além do bloco de atributos relacionados a aparência, definido por alguns adjetivos não se encaixarem nos dois blocos anteriores.

\section{Dimensão da Aparência}

Foram considerados nesta dimensão o adjetivo "bonitos" que está relacionado à percepção de atributos físicos em termos de atratividade, o adjetivo "vaidosos" que está relacionado à percepção do quanto o indivíduo se dedica e se preocupa com os cuidados com a sua aparência física. Também foram colocados nesta dimensão o adjetivo "legal", gíria muito usada entre adolescentes que segundo o Dicionário Aurélio, que refere-se a algo que é tão bom quanto se espera que seja, entendendo-se que esse adjetivo se refere a uma aparência relacional que se refere à possibilidade em estabelecer e manter um contato agradável ou não. Incluíram-se nesta mesma noção os adjetivos "convencidos" e "metidos". $\mathrm{Na}$ análise do adjetivo "legal" não foram identificadas evidências estatísticas que sugerissem diferença na atribuição desse para os grupos avaliados com relação às variáveis analisadas.

\section{A) Bonito}

A Tabela 1 oferece as médias das respostas dos participantes de ambos os sexos e alunos das escolas confessional e leiga para os grupos alvo $[\mathrm{F}(1,235)=$ $5,796, \mathrm{p}=0,017)]$.

\section{TABELA 1}

Médias e Desvio Padrão das Atribuições do Adjetivo "Bonito" aos Alvos Femininos e Masculinos em Função da Interação Entre as Variáveis Escola e Sexo (Entre Parênteses)

\begin{tabular}{lc|cc|c}
\hline \multirow{2}{*}{ Alvos } & \multicolumn{2}{c}{ Escola confessional } & \multicolumn{2}{c}{ Escola leiga } \\
\cline { 2 - 5 } & Elas & Eles & Elas & Eles \\
\hline As adolescentes & 4,13 & 4,23 & 3,95 & 4,20 \\
& $(0,77)$ & $(0,43)$ & $(0,70)$ & $(0,51)$ \\
Os adolescentes & 3,90 & 2,57 & 3,63 & 2,97 \\
& $(0,71)$ & $(1,44)$ & $(0,78)$ & $(1,36)$ \\
\hline
\end{tabular}

Nota. $p<0.05$

Como é possível verificar, as aplicações do adjetivo para as adolescentes apresentam as maiores médias, independente do sexo do avaliador e da escola que ele frequenta. É possível observar que não ocorre variação entre as médias das respostas dos participantes masculinos de ambos os colégios quando avaliam as adolescentes como bonitas e, também, que eles apresentam as médias de respostas mais intensas. Ou seja, os rapazes são os que mais valorizam esse atributo para as adolescentes. Contudo, quando se observa as respostas deles para o alvo masculino, verifica-se que são menos intensas que as repostas das meninas para o mesmo grupo, sendo que os meninos, alunos do colégio confessional, são os que menos atribuem esse adjetivo a grupo masculino.

Avaliando a média das repostas com relação ao sexo dos participantes da pesquisa $[\mathrm{F}(1,235)=23,644$ $=0,000]$, observa-se que as participantes avaliaram o alvo feminino $(\mathrm{M}=4,04$; $\mathrm{DP}=0,74)$ como mais bonitas que o alvo masculino $(\mathrm{M}=3,76$; $\mathrm{DP}=0,76)$. Já os meninos valorizam mais esse atributo no grupo externo $(\mathrm{M}=4,22 ; \mathrm{DP}=0,47)$ que no próprio grupo $(\mathrm{M}=$
$2,77$; DP $=1,41)$. Neste caso, observa-se que os rapazes tendem a desprezar esse atributo na avaliação do seu grupo. Essa tendência talvez tenha, ainda hoje, uma relação com o padrão de comportamento social desejado para os homens, a partir do qual se espera que homens não achem outros homens bonitos, não se ocupem em avaliar o padrão de beleza masculina. Por outro lado, parece que o fato de ser mulher permite que elas avaliem ambos os sexos como fisicamente atraentes demonstrando, contudo, que acham os membros do próprio grupo mais bonitos que o grupo masculino. Isso indica um padrão de comportamento social diferenciado para o grupo feminino que parece não considerar um problema para a feminilidade valorizar e notar a beleza física em pessoas do mesmo gênero.

Quando foi pedido aos participantes para dizerem como eles pensavam que o grupo externo os via, a análise das respostas para a metapercepção apontou resultados relevantes para a variável escola $[\mathrm{F}(1,235)$ $=5,945 ; \mathrm{p}=0,016]$. Os alunos, de ambos os sexos, da escola confessional $(\mathrm{M}=3,95$; $\mathrm{DP}=0,83)$ apresentaram uma metapercepção mais acentuada sobre este 
atributo em comparação com os alunos da escola leiga $(\mathrm{M}=3,67 ; \mathrm{DP}=0,98)$. Isso sugere que tantos os meninos quanto as meninas dessa escola esperam ser vistos como mais bonitos pelo sexo oposto que os alunos da escola leiga.

As respostas de acordo com o sexo dos participantes $[\mathrm{F}(1,235)=5,945 ; \mathrm{p}=0,016]$ indicam que as adolescentes apresentam uma expectativa maior em serem vistas pelos meninos como bonitas $(\mathrm{M}=3,95$; $\mathrm{DP}=$ 0,82 ), em comparação à expectativa que eles apresentam em serem vistos como bonitos por elas $(\mathrm{M}=3,67$; $\mathrm{DP}=1,00)$. Esse resultado se ajusta ao que foi obtido na análise dos auto e heteroestereótipos, no qual observa-se que as meninas apresentam uma tendência a se avaliarem como bonitas mais que os meninos. Dessa forma, elas também esperam que eles as avaliem como sendo bonitas. Já os meninos, apesar de não se verem como bonitos, esperam que as meninas os vejam como tal.

\section{B) Vaidoso}

Observando a Tabela 2, na qual são apresentados os resultados das repostas com relação ao sexo e escola dos participantes $[\mathrm{F}(1,235)=17,322 ; \mathrm{p}=0,000]$, é possível notar que de modo geral as adolescentes são vistas como vaidosas por todos os participantes, sendo que as alunas da escola confessional são as que mais atribuem a característica ao alvo. Nota-se, também, que existe uma variação maior entre as respostas dos alunos da escola confessional com relação ao sexo. Ou seja, as alunas atribuiriam mais esse adjetivo ao grupo alvo que os alunos. É possível observar através dos resultados que, enquanto são as alunas da escola confessional que percebem as meninas como mais vaidosas, na escola leiga são os meninos que as percebem assim, mais que os meninos da escola confessional.

TABELA 2

Médias e Desvio Padrão das Atribuições do Adjetivo "Vaidoso" aos Alvos Femininos e Masculinos em Função da Interação Entre as Variáveis Escola e Sexo (Entre Parênteses)

\begin{tabular}{lc|cc|c}
\hline \multirow{2}{*}{ Alvos } & \multicolumn{2}{c}{ Escola confessional } & \multicolumn{2}{c}{ Escola leiga } \\
\cline { 2 - 5 } & Elas & Eles & Elas & Eles \\
\hline As adolescentes & 4,86 & 4,53 & 4,57 & 4,68 \\
& $(0,34)$ & $(0,87)$ & $(0,50)$ & $(0,47)$ \\
Os adolescentes & 4,05 & 3,47 & 3,58 & 4,00 \\
& $(1,06)$ & $(1,38)$ & $(1,11)$ & $(0,92)$ \\
\hline
\end{tabular}

Nota. $p<0.05$.

Quando o alvo da avaliação são eles, observa-se que a média de repostas é inferior às que são feitas para elas, ou seja, eles também são considerados vaidosos, mas não tanto quanto elas. Também, para este grupo, são as alunas da escola confessional que apresentam maior média de respostas seguidas pelos alunos da escola leiga.

Analisando a metapercepção, observa-se que, de acordo com a média das repostas das adolescentes $(\mathrm{M}=4,80 ; \mathrm{DP}=0,40)$ em comparação com a média das repostas dos adolescentes $(\mathrm{M}=3,34$; $\mathrm{DP}=1,31)$, pode-se dizer que elas esperam ser vistas por eles como vaidosas muito mais que eles acreditam serem percebidos como tal por elas. Isso indica que o gênero foi uma variante importante na percepção dos participantes $[\mathrm{F}(1,235)=134,276 ; \mathrm{p}=0,000]$.

As mulheres se sobressaem nas atribuições dessa característica (vaidosas), tanto na visão delas sobre o próprio grupo quanto na forma como são percebidas pelo grupo externo e, também, por esperarem serem vistas por ele como vaidosas. Por outro lado, a percepção dos homens como vaidosos vem sendo mais notada tanto na avaliação delas sobre eles quanto na autoavaliação deles, e de forma mais sutil na metapercepção. Ou seja, eles não acreditam muito que elas os vejam assim.

\section{C) Vulgar}

As respostas dos participantes na atribuição deste adjetivo revelam que a opinião dos meninos sobre as adolescentes $(\mathrm{M}=2,96 ; \mathrm{DP}=1,25)$ é a mesma que eles têm sobre o grupo feminino $(\mathrm{M}=2,96$; $\mathrm{DP}=$ 1,33). Por outro lado, as opiniões das meninas apresentam diferenças quando elas avaliam o alvo masculino $(\mathrm{M}=2,67 ; \mathrm{DP}=1,22)$ e quando elas avaliaram o próprio grupo $(\mathrm{M}=2,56 ; \mathrm{DP}=1,17)$. Esses resultados 
indicam que o sexo dos participantes é um fator de interferência na atribuição do adjetivo vulgar $[F(1,235)=7,356 ; p=0,007]$ e que os homens são os que mais utilizam o adjetivo na caracterização de ambos os grupos. As meninas, por sua vez, valorizam menos esse atributo na caracterização do seu grupo que na caracterização dos meninos.

\section{D) Convencido}

Observando as respostas dos participantes de cada escola é possível identificar uma maior variação entre as atribuições dos alunos da escola confessional ( $\mathrm{M}=3,91$; $\mathrm{DP}=0,89)$ e dos alunos da escola leiga $(\mathrm{M}=3,45$; $\mathrm{DP}=1,23$ ) dirigidas ao alvo feminino. Quando o alvo das avaliações era masculino, as médias das respostas dos alunos da escola confessional $(\mathrm{M}=3,77$; $\mathrm{DP}=1,11)$ e dos alunos da escola leiga $(\mathrm{M}=3,72$; $\mathrm{DP}=1,19)$ foram bastante semelhantes. Esse resultado sugere que a escola $[\mathrm{F}(1,235)=7,126 ; \mathrm{p}=0,008]$ é um fator que pode influenciar nas avaliações dos adolescentes sendo que os alunos da escola confessional atribuem mais esse adjetivo que os alunos da escola leiga. Também, pode-se sugerir que o fato de ser aluno da escola confessional leve os adolescentes a perceberem as meninas como mais convencidas em comparação com os meninos e o fato de ser aluno do colégio leigo leve os adolescentes a perceberem as meninas como menos convencidas que os meninos.

As médias das atribuições do adjetivo convencido com relação ao sexo dos participantes $[\mathrm{F}(1,235)=$ $5,012 ; \mathrm{p}=0,026]$ indicam que elas tendem a atribuir menos essa característica $(\mathrm{M}=3,45 ; \mathrm{DP}=1,17)$ para o grupo feminino que eles $(\mathrm{M}=3,91, \mathrm{DP}=0,97)$. Quando o alvo da atribuição é o grupo masculino, elas $(\mathrm{M}=4,19 ; \mathrm{DP}=0,85)$ atribuem mais a característica que eles $(M=3,30 ; \mathrm{DP}=1,23)$. Esses dados revelam uma tendência dos participantes atribuírem mais essa característica ao grupo externo. Ou seja, os meninos consideram que as meninas são mais convencidas que eles e vice-versa.

A análise de metapercepção $[\mathrm{F}(1,235)=6,841 ; \mathrm{p}=$ $0,009]$ sobre este adjetivo revelou que as meninas acreditam ser percebidas como convencidas pelos meninos $(\mathrm{M}=4,27 ; \mathrm{DP}=0,92)$ e eles também esperam ser vistos assim por elas, porém com menor intensidade $(\mathrm{M}=$ 3,93; $\mathrm{DP}=1,05)$. Esses resultados demonstram que as meninas são vistas e esperam ser vistas como convencidas, muito mais que se consideram assim. O mesmo ocorreu com os rapazes. Pode-se dizer que existe uma concordância entre autoestereótipos, heteroestereótipos e metapercepção. Contudo, a relação entre heteroestereótipos e metapercepção é mais próxima.

\section{E) Metido}

As médias da atribuição do adjetivo metido às meninas obtidas na escola confessional $(\mathrm{M}=4,01$; $\mathrm{DP}=$ $0,97)$ e na escola leiga $(M=3,48 ; D P=1,08)$ em comparação com as médias obtidas na escola confessional $(\mathrm{M}=3,39 ; \mathrm{DP}=1,22)$ e na escola leiga $(\mathrm{M}=$ 3,37 ; $\mathrm{DP}=1,14$ ) na avaliação dos meninos demonstram que enquanto não ocorre diferença na forma como eles são percebidos pelos participantes de ambas as escolas, existe uma variação acentuada na forma como elas são percebidas pelos dois grupos. A atribuição deste adjetivo para elas é mais intensa entre os alunos do colégio confessional. Também é possível dizer que os alunos da escola leiga, avaliam as adolescentes como mais metidas que os adolescentes, ao contrário do que ocorre com as atribuições dos alunos da escola confessional. Parece que o fato de ser aluno da escola confessional leva os adolescentes a perceberem as mulheres como mais metidas, sendo a escola indicada como um fator relevante na atribuição deste adjetivo $[\mathrm{F}(1,235)=6,829 ; \mathrm{p}=0,010]$.

Analisando as repostas de acordo com o sexo dos participantes $[\mathrm{F}(1,235)=3,944 ; \mathrm{p}=0,048]$, nota-se que, nas avaliações realizadas por elas, os meninos $(\mathrm{M}=3,74$; $\mathrm{DP}=1,05)$ foram considerados mais metidos que as meninas $(\mathrm{M}=3,61$; $\mathrm{DP}=1,05)$. Nas atribuições realizadas por eles, as meninas ( $\mathrm{M}=$ $3,89, \mathrm{DP}=105$ ) foram vistas como mais metidas que os meninos $(\mathrm{M}=3,03$; $\mathrm{DP}=1,20)$. Esse resultado indica que existe uma tendência em valorizar mais esse atributo como característico do grupo externo. No entanto, nas atribuições feitas pelos meninos, observa-se uma distância maior entre a média de suas atribuições feitas os grupos feminino e masculino, enquanto que nas atribuições delas não se verifica uma diferença marcante entre as opiniões sobre o próprio grupo e o grupo externo. Ou seja, os meninos são os que mais utilizam esse atributo na caracterização do grupo feminino e os que menos utilizam na caracterização do seu grupo.

A análise indicou que na metapercepção a variável sexo é relevante para esse dado $[\mathrm{F}(1,235)=26,252$; $\mathrm{p}=0,000]$, uma vez que, apesar, de ambos os grupos acreditarem que são vistos como metidos pelo grupo externo. A média das repostas das adolescentes ( $\mathrm{M}=$ $4,30 ; \mathrm{DP}=0,94)$ indica que elas acreditam ser vistas como metidas de forma mais marcante do que eles $(\mathrm{M}=3,60 ; \mathrm{DP}=1,16)$. Os resultados apontam para 
uma concordância entre os três níveis de análise dos estereótipos, mas que tanto elas quanto eles são vistos e esperam ser vistos assim, de forma mais acentuada a sua autopercepção. Essa tendência foi mais marcante entre as meninas.

\section{Dimensão Expressiva}

Os estudos sobre estereótipos de gênero separam os atributos que associam traços de personalidade à construção sociocultural da masculinidade e feminilidade. Assim os atributos masculinos são definidos por traços instrumentais ou individualistas, enquanto os femininos são definidos por traços expressivos ou coletivistas. Aqui, foram considerados como atributos expressivos os adjetivos delicado, romântico, sensível, sincero, companheiro, organizado e responsável.

\section{A) Delicado}

Analisando os resultados apresentados pelos participantes de cada escola $[\mathrm{F}(1,235)=4,331, \mathrm{p}=0,004]$ pode-se observar que apesar das meninas serem, de modo geral, avaliadas como delicadas, são os participantes da escola confessional que tendem a valorizar mais esse atributo nas suas avaliações sobre o grupo feminino $(\mathrm{M}=4,45, \mathrm{DP}=0,93)$ em comparação aos participantes da escola leiga $(\mathrm{M}=4,15$; $\mathrm{DP}=0,88)$. Os meninos, por outro lado, não são vistos como deli- cados e, observa-se uma variação bem menor entre as avaliações feitas pelos alunos da escola confessional $(\mathrm{M}=1,99, \mathrm{DP}=1,17)$ e alunos da escola leiga $(\mathrm{M}=$ $1,91 ; \mathrm{DP}=0,98)$ sobre este grupo.

Nos resultados da interação entre escola e sexo dos participantes $[\mathrm{F}(1,235)=10,066, \mathrm{p}=0,002]$ apresentados na Tabela 3, observa-se que, quando o alvo da avaliação são as adolescentes, as alunas do colégio confessional atribuem essa característica com mais intensidade que as alunas da escola leiga. Os dados sugerem que o fato de ser mulher e estudar no colégio confessional leva o avaliador a perceber o grupo feminino como mais delicado, enquanto o fato de ser mulher e estudar da escola leiga leva o avaliador a perceber este mesmo grupo como menos delicado. Observa-se um resultado semelhante na avaliação feita pelos meninos.

Quando o alvo são os adolescentes, a maior média de resposta é fornecida pelas alunas da escola confessional, e a menor pelos alunos da mesma escola. Os resultados sugerem que o fato de ser homem e aluno do colégio confessional faz com que o participante tenda a perceber os membros do grupo masculino como não sendo delicados, enquanto o fato de ser do mulher e estudar no mesmo colégio faz com que elas os percebam como mais delicados.

TABELA 3

Médias e Desvio Padrão das Atribuições do Adjetivo "Delicado" aos Alvos Femininos e Masculinos em Função da Interação Entre as Variáveis Escola e Sexo (Entre Parênteses)

\begin{tabular}{lc|cc|c}
\hline \multirow{2}{*}{ Alvos } & \multicolumn{2}{c}{ Escola confessional } & \multicolumn{2}{c}{ Escola leiga } \\
\cline { 2 - 5 } & Elas & Eles & Elas & Eles \\
\hline As adolescentes & 4,49 & 4,40 & 4,03 & 4,27 \\
& $(0,82)$ & $(1,03)$ & $(0,97)$ & $(0,78)$ \\
Os adolescentes & 2,27 & 1,72 & 1,77 & 2,05 \\
& $(1,35)$ & $(0,90)$ & $(0,95)$ & $(1,01)$ \\
\hline
\end{tabular}

Nota. $p<0.05$.

$\mathrm{Na}$ análise das repostas sobre a metapercepção, observa-se a partir da média das respostas que elas $(\mathrm{M}=$ 4,30 ; $\mathrm{DP}=0,84$ ) acreditam serem vistas como delicadas por eles, enquanto eles tendem a não acreditar que são vistos assim por elas $(\mathrm{M}=2,12 ; \mathrm{DP}=1,18)$, o que indica o sexo do participante como um fator importante na metapercepção deste atributo $[\mathrm{F}(1,235)=269,224$; $\mathrm{p}=0,000]$. O resultado demonstra que existe uma correspondência entre autoestereótipos, heteroestereótipos e metapercepção na atribuição dessa característica para ambos os sexos, indicando uma tendência na manutenção do estereótipo que salienta características expressivas para as mulheres, e não para os homens.

\section{B) Romântico}

A análise indicou o efeito principal da escola na atribuição desse adjetivo $[\mathrm{F}(1,235)=10,844, \mathrm{p}=$ $0,001]$. Os dados apontam que as meninas são consi- 
deradas mais românticas pelos alunos da escola confessional $(M=4,30 ; \mathrm{DP}=0,98)$ que pelos alunos da escola leiga $(\mathrm{M}=3,95 ; \mathrm{DP}=1,10)$. O mesmo é observado na atribuição do adjetivo aos meninos que são considerados menos românticos pelos alunos da escola leiga $(\mathrm{M}=2,63 ; \mathrm{DP}=1,27)$ que pelos alunos da escola confessional $(M=3,03 ; \mathrm{DP}=1,30)$. Assim, se as meninas são consideradas românticas, são os alunos da escola confessional que mais as percebem desta forma; e se os homens não são considerados românticos, são os alunos da escola leiga que mais confirmam essa percepção.

Analisando os dados da metapercepção foi possível identificar que o sexo dos participantes foi um fator relevante $[\mathrm{F}(1,235)=144,125 ; \mathrm{p}=0,000]$. De acordo com o resultado, as adolescentes $(\mathrm{M}=4,40 ; \mathrm{DP}=$ $1,05)$ acreditam que são vistas como românticas pelos rapazes enquanto eles $(\mathrm{M}=2,58 ; \mathrm{DP}=1,31)$ já não esperam que elas os vejam assim.

Os resultados da metapercepção ainda indicaram interação entre a escola e o sexo dos participantes $[\mathrm{F}(1,235)=4,478 ; \mathrm{p}=0,035]$. A média das respostas demonstra que não ocorre muita variação da metapercepção entre as alunas da escola leiga $(\mathrm{M}=4,47$, DP $=1,03)$ e as alunas da escola confessional $(\mathrm{M}=4,34$,
$\mathrm{DP}=1,08)$, sendo que nas duas escolas elas esperam ser vistas pelos meninos como românticas. Entretanto, as alunas da escola leiga acreditam mais nisso. Por outro lado, existe uma variação expressiva entre os alunos do colégio leigo $(\mathrm{M}=2,32, \mathrm{DP}=1,24)$ e os alunos do colégio confessional $(\mathrm{M}=2,83, \mathrm{DP}=1,33)$ sugerindo que, apesar de os meninos de ambas as escolas não esperarem muito que as meninas os percebam como românticos, os que estudam no colégio leigo são os que menos acreditam serem vistos assim.

\section{C) Sensível}

Analisando os resultados das repostas com relação à interação entre sexo e escola $[\mathrm{F}(1,235)=3,984, \mathrm{p}=$ $0,047]$ apresentadas na Tabela 4, pode-se observar que, de modo geral, as adolescentes são vistas como mais sensíveis que os adolescentes. Contudo, quando o alvo da avaliação são elas, observa-se que os meninos, alunos da escola confessional, concordam com esse atributo de forma mais intensa que os outros participantes. Já as meninas, alunas da escola leiga, são as que menos atribuem a característica ao grupo feminino. Os dados revelam que a crença nesse atributo para o grupo feminino é mais forte entre os alunos de ambos os sexos da escola confessional.

TABELA 4

Médias e Desvio Padrão das Atribuições do Adjetivo Sensivel aos Alvos Femininos e Masculinos em Função da Interação Entre as Variáveis Escola e Sexo (Entre Parênteses)

\begin{tabular}{lc|cc|c}
\hline \multirow{2}{*}{ Alvos } & \multicolumn{2}{c}{ Escola confessional } & \multicolumn{2}{c}{ Escola leiga } \\
\cline { 2 - 5 } & Elas & Eles & Elas & Eles \\
\hline As adolescentes & 4,61 & 4,84 & 4,25 & 4,33 \\
& $(0,81)$ & $(0,70)$ & $(0,95)$ & $(0,91)$ \\
Os adolescentes & 2,53 & 2,17 & 2,23 & 2,45 \\
& $(1,36)$ & $(1,22)$ & $(1,17)$ & $(1,16)$ \\
\hline
\end{tabular}

Nota. $p<0.05$

Quando o alvo da avaliação são eles, observa-se que os meninos, alunos da escola confessional são os que menos concordam com a atribuição e são meninas, as alunas da mesma escola, as que veem os meninos como não sendo sensíveis. Ainda é possível notar que os alunos da escola confessional concordam menos com esse atributo que os alunos da escola leiga e as alunas da escola leiga percebem os meninos como menos sensíveis que as alunas da escola confessional.

$\mathrm{Na}$ análise da metapercepção, o sexo aparece como um fator importante nas atribuições $[\mathrm{F}(1,235)=$
387,352; $\mathrm{p}=0,000]$. A média de respostas das adolescentes $(M=4,66$; $D P=0,69)$ indica que elas esperam ser vistas como sensíveis pelos meninos. As repostas deles $(M=2,24 ; D P=1,15)$, por outro lado, indicam que eles não esperam que sejam vistos dessa forma por elas. Esses resultados revelam que o adjetivo sensível é visto como uma característica mais feminina que masculina e que existe uma equivalência entre os membros de ambos os grupos na forma como pensam sobre os membros do grupo a que pertencem e, também, sobre como são vistos e como esperam ser vistos pelos membros do grupo externo. 


\section{D) Sincero}

A análise indica o efeito principal da variável escola $[\mathrm{F}=(1,235)=4,273=0,040]$ na atribuição desse adjetivo. Existe uma variação maior entre as médias das repostas dos alunos da escola confessional $(\mathrm{M}=$ 3,71; $\mathrm{DP}=2,25)$ e das repostas dos alunos da escola leiga $(\mathrm{M}=3,07$; $\mathrm{DP}=1,23)$ quando o alvo da atribuição é feminino, enquanto as atribuições para o alvo masculino revelam que o nível de concordância com este atributo é praticamente o mesmo entre alunos da escola confessional $(\mathrm{M}=3,15 ; \mathrm{DP}=1,31)$ e alunos da escola leiga $(M=3,19$; $D P=1,34)$. Pode-se observar através das médias que as adolescentes são percebidas como sinceras mais pelos alunos da escola confessional que pelos alunos da escola leiga. Quando o alvo é o grupo masculino, o inverso ocorre, ainda que de forma bem menos marcante que a avaliação do grupo feminino.

\section{E) Companheiro}

Observa-se interação entre sexo e escola dos participantes $[\mathrm{F}(1,235)=4,371 ; p=0,038]$ na atribuição dessa característica. As médias das respostas na Tabela 5 demonstram que quando o alvo são elas, as alunas da escola confessional são as que concordam com a atribuição de forma mais intensa. A média desta avaliação dos meninos, de ambas as escolas, sobre elas, são semelhantes. Quando o alvo são eles, os meninos da escola leiga são os que mais concordam com a atribuição e as meninas, da mesma escola, as que menos atribuem esse adjetivo aos rapazes.

TABELA 5

Médias e Desvio Padrão das Atribuições do Adjetivo "Companheiro" aos Alvos Femininos e Masculinos em Função da Interação Entre as Variáveis Escola e Sexo (Entre Parênteses)

\begin{tabular}{lc|cc|c}
\hline \multirow{2}{*}{ Alvos } & \multicolumn{2}{c}{ Escola confessional } & \multicolumn{2}{c}{ Escola leiga } \\
\cline { 2 - 5 } & Elas & Eles & Elas & Eles \\
\hline As adolescentes & 4,56 & 3,90 & 4,23 & 3,88 \\
& $(0,59)$ & $(1,08)$ & $(0,89)$ & $(1,01)$ \\
Os adolescentes & 3,86 & 3,87 & 3,75 & 4,25 \\
& $(1,06)$ & $(1,10)$ & $(0,97)$ & $(0,95)$ \\
\hline
\end{tabular}

Nota. $p<0.05$.

A análise da metapercepção sobre esse adjetivo revela que as adolescentes $(\mathrm{M}=4,01$; $\mathrm{DP}=0,97)$ esperam ser vistas como companheiras pelos meninos mais do que eles esperam ser vistos, assim, por elas $(\mathrm{M}=3,72 ; \mathrm{DP}=1,12)$. Esse resultado indica que o sexo dos participantes é um fator importante na metapercepção dos adolescentes sobre esse atributo [F $(1,235)=4,691 ; \mathrm{p}=0,031]$.

\section{F) Organizado}

Ao analisar as médias das repostas dos participantes com relação à escola que frequentam $[\mathrm{F}(1,235)=$ $13,105 ; p=0,000]$, observa-se que na avaliação das mulheres como sendo organizadas existe uma variação maior no nível de concordância dessa atribuição entre as escolas, sendo ela mais intensa entre os participantes da escola confessional $(\mathrm{M}=4,39$; $\mathrm{DP}=0,95)$ que entre os participantes da escola leiga $(\mathrm{M}=$ de 3,69; DP = 1,11). Quando o alvo da avaliação é o grupo masculino quase não se observa variação entre as repostas dos participantes da escola confessional $(\mathrm{M}=2,11 ; \mathrm{DP}=1,24)$ e participantes da escola leiga $(\mathrm{M}=2,03 ; \mathrm{DP}=1,19)$.

O sexo dos participantes também aparece como fator relevante nas atribuições $[\mathrm{F}(1,235)=4,408$, p = $0,037]$, uma vez que as médias das respostas indicam que quando o alvo da atribuição é o grupo feminino existe uma tendência dos participantes, tanto femininos $(\mathrm{M}=4,05, \mathrm{DP}=1,08)$ quanto masculinos $(\mathrm{M}=4,03$, $\mathrm{DP}=1,10)$, concordarem, na mesma intensidade, com a caracterização. Quando o alvo é o grupo masculino, observa-se uma tendência dos participantes não concordarem com essa caracterização, sendo que elas $(\mathrm{M}=$ $1,83, \mathrm{DP}=1,08)$ tendem a concordar menos que eles $(\mathrm{M}=2,31, \mathrm{DP}=1,30)$ com a atribuição.

$\mathrm{Na}$ análise dos dados da metapercepção quanto a variável sexo $[\mathrm{F}(1,235)=238,617 ; \mathrm{p}=0,000]$, observa-se que elas esperam que eles as percebam como organizadas $(M=4,17 ; \mathrm{DP}=1,17)$, enquanto eles acreditam não serem vistos, assim, por elas $(M=1,83$; 
DP $=1,18)$. Observa-se uma correspondência entre os resultados dessa atribuição nos três níveis analisados, autoestereótipo, heteroestereótipo e metapercepção tanto para o alvo feminino, elas se percebem, são percebidas e esperam ser percebidas como organizadas, quanto para o alvo masculino, eles não se veem, não são vistos e nem esperam ser vistos como organizados.

\section{G) Responsável}

$\mathrm{Na}$ atribuição desse adjetivo verificou-se uma tendência das meninas serem vistas como mais responsáveis pelos participantes da escola confessional $(\mathrm{M}=$ $4,07 ; \mathrm{DP}=1,01)$ que pelos participantes da escola leiga $(M=3,65$; $\mathrm{DP}=1,07)$. As respostas obtidas para o grupo alvo masculino, tanto na escola confessional $(\mathrm{M}=2,96 ; \mathrm{DP}=1,28)$ quanto na escola leiga $(\mathrm{M}=$ 2,$71 ; \mathrm{DP}=1,18$ ) indicam que eles tendem a ser percebidos como menos responsáveis que elas. Os que menos percebem os meninos como responsáveis são os alunos da escola leiga. A escola aparece, aqui, como fator relevante nesta atribuição $[\mathrm{F}(1,235)=9,164 ; \mathrm{p}=$ 0,003 ] e os participantes da escola confessional são os que mais utilizam esse atributo na avaliação de ambos os grupos.

Quando as atribuições desse adjetivo são analisadas com relação ao sexo dos participantes $[\mathrm{F}(1,235)=$ $4,219 ; \mathrm{p}=0,041]$, foi verificada a tendência das meninas $(\mathrm{M}=3,92 ; \mathrm{DP}=1,06)$ atribuírem mais que os meninos $(\mathrm{M}=3,80 ; \mathrm{DP}=1,06)$, a característica ao grupo feminino. Já, quando o alvo da atribuição são eles, o inverso ocorreu. Eles $(\mathrm{M}=3,12 ; \mathrm{DP}=1,24)$, mais do que elas $(\mathrm{M}=2,55$; $\mathrm{DP}=1,16)$, percebem-se como responsáveis. Esses resultados revelam a ocorrência de uma variação maior entre as atribuições desse adjetivo feitas por participantes de ambos os sexos na caracterização do alvo masculino que na do alvo feminino. Também indica que ocorre uma valorização maior desse atributo na avaliação do próprio grupo que na do grupo externo, e que as mulheres são percebidas como mais responsáveis que os homens, independente do sexo do avaliador. Ou seja, os participantes de ambos os sexos valorizam o atributo como mais característico do grupo feminino.

A análise da metapercepção indicou que existe efeito da variável sexo $[\mathrm{F}(1,235)=55,032 ; \mathrm{p}=0,000]$ e mostra que as adolescentes $(M=3,92 ; \mathrm{DP}=1,09)$ têm uma tendência maior em acreditar que são vistas como responsáveis pelos meninos. Os meninos $(\mathrm{M}=$ 2,78 ; $\mathrm{DP}=1,29$ ), por sua vez, não acreditam que elas o vejam como responsáveis.

Pode-se dizer, então, que a percepção das meninas como responsáveis ocorre de forma semelhante nos três níveis de análise. O mesmo ocorre com a avaliação do grupo masculino. Esse grupo, contudo, não é visto como responsável nos três níveis de análise.

\section{Dimensão Instrumental}

Foram considerados nesta dimensão os adjetivos estudioso, inteligente, persistente, agressivo, autoritário, arrogante, farrista e inconsequente.

\section{A) Estudioso}

As respostas obtidas para este adjetivo revelaram que as meninas são vistas como mais estudiosas pelos participantes da escola confessional $(\mathrm{M}=4,08$; $\mathrm{DP}=$ $0,94)$ que pelos participantes da escola leiga $(\mathrm{M}=$ $3,68$; DP $=1,00)$. Os meninos, também, são vistos como mais estudiosos pelos participantes da escola confessional $(\mathrm{M}=3,09 ; \mathrm{DP}=1,18)$ que pelos participantes da escola leiga $(\mathrm{M}=2,75$; $\mathrm{DP}=1,12)$. Esse resultado indica efeito da escola nas atribuições realizadas $[\mathrm{F}(1,235)=11,590 ; \mathrm{p}=0,001]$ e demonstra que mesmo a valorização deste adjetivo sendo maior na escola confessional, para ambos os grupos, as meninas são vistas como estudiosas numa proporção maior que os meninos, em ambas as escolas.

Na análise da metapercepção a variável sexo é um fator relevante na atribuição desse adjetivo $[\mathrm{F}(1,235)$ $=109,724 ; \mathrm{p}=0,000]$. A média das respostas fornecidas pelos participantes masculinos $(\mathrm{M}=2,54$; $\mathrm{DP}=$ $1,15)$ indica que eles não acham que são vistos por elas como estudiosos. Elas ( $\mathrm{M}=4,04$; $\mathrm{DP}=1,08)$, por outro lado, acham que os meninos as como estudiosas.

Os dados também indicam que a variável escola $[\mathrm{F}$ $(1,235)=4,415 ; p=0,037$ ] é relevante para as análises, uma vez que comparando as médias das respostas apresentadas pelos alunos da escola confessional $(\mathrm{M}=$ 3,44 ; $\mathrm{DP}=1,30$ ) com a média das respostas dos alunos da escola leiga $(\mathrm{M}=3,14 ; \mathrm{DP}=1,37)$ pode-se dizer que a metapercepção é maior entre os alunos da escola confessional que entre os alunos da escola leiga. Aqueles esperam mais que sejam vistos como estudiosos que estes.

\section{B) Inteligente}

Observando as médias das repostas sobre a atribuição do adjetivo inteligente, verifica-se que quando o alvo é o grupo feminino obtém-se uma média de respostas maior na escola confessional $(\mathrm{M}=4,18$; $\mathrm{DP}=$ $0,76)$ que na escola leiga $(\mathrm{M}=3,88 ; \mathrm{DP}=0,95)$. Quando o alvo é o grupo masculino, as médias de repostas obtidas na escola confessional $(\mathrm{M}=3,89$; $\mathrm{DP}=1,02)$ e na escola leiga $(\mathrm{M}=3,70 ; \mathrm{DP}=1,04)$ 
foram bastante próximas, porém com mais intensidade na escola confessional. Pode-se dizer que sendo a escola um fator relevante nas atribuições desse adjetivo aos alvos $[\mathrm{F}(1,235)=7,710 ; \mathrm{p}=0,006]$, o aluno do colégio confessional teria mais disposição para reconhecer esse adjetivo como um atributo característico, tanto do grupo feminino quando do grupo masculino. Esta disposição é ainda maior nas atribuições feitas ao grupo feminino.

\section{C) Persistente}

Nas atribuições deste adjetivo, observa-se que quando o alvo são os meninos existe uma variação maior das respostas dos participantes entre as escolas, sendo que eles são vistos como mais persistentes pelos participantes da escola confessional $(\mathrm{M}=4,18$; $\mathrm{DP}=$ $0,99)$ que pelos da escola leiga $(\mathrm{M}=3,91 ; \mathrm{DP}=1,06)$. Quando o alvo da avaliação são as meninas, apesar da variação das respostas entre as escolas ser pequena, observa-se, também na escola confessional $(\mathrm{M}=3,92$; $\mathrm{DP}=1,16)$, uma atribuição maior dessa característica ao grupo que nas respostas dos participantes na escola leiga $(\mathrm{M}=3,79 ; \mathrm{DP}=1,05)$. Esses resultados indicam que apesar de ambos os grupos serem vistos como persistentes pelos avaliadores, os meninos parecem ser percebidos, assim, mais intensamente. A escola como um fator significativo na atribuição dessa característica $[\mathrm{F}(1,235)=4,107 ; \mathrm{p}=0,044]$, indica que os alunos da escola confessional são os que mais valorizam esse atributo para ambos os grupos avaliados, sendo o grupo masculino visto como mais persistente.

Avaliando as respostas com relação ao sexo dos participantes $[\mathrm{F}(1,235)=7,634 ; \mathrm{p}=0,006]$, observa-se que as meninas ( $M=4,27 ; \mathrm{DP}=0,85)$, mais que os meninos $(\mathrm{M}=3,45 ; \mathrm{DP}=1,19)$, avaliam o grupo feminino como persistentes. Contudo, quando o alvo da avaliação é o grupo masculino, são eles que avaliam o grupo como mais persistente $(\mathrm{M}=4,18 ; \mathrm{DP}=0,94)$, e não elas $(\mathrm{M}=$ 3,$92 ; \mathrm{DP}=1,11$ ). Observa-se que são os meninos que consideram as meninas menos persistentes.

Pode-se dizer que na atribuição desse adjetivo existe uma tendência a percebê-lo como mais característico do próprio grupo que do grupo externo.

\section{D) Agressivo}

Os resultados da análise demonstraram ausência de significância estatística quanto às variáveis sexo e escola na atribuição desse adjetivo. Contudo, a análise da metapercepção indicou o efeito da variável sexo nessa atribuição $[\mathrm{F}(1,235)=25,405 ; \mathrm{p}=0,000]$. De acordo com o resultado, as médias das respostas indicam que os adolescentes $(\mathrm{M}=3,76 ; \mathrm{DP}=1,20)$ acreditam que são percebidos como mais agressivos pelas adolescentes do que elas $(\mathrm{M}=2,94$; $\mathrm{DP}=1,31)$ pensam ser percebidas, assim, pelo grupo masculino.

\section{E) Autoritário}

Os resultados da análise indicaram efeito da variável sexo $[\mathrm{F}(1,235)=7,525 ; \mathrm{p}=0,007]$. Observa-se que, quando o alvo da análise é feminino, as adolescentes concordam mais com a atribuição $(\mathrm{M}=3,87$; $\mathrm{DP}=1,10)$ que os adolescentes $(\mathrm{M}=3,63, \mathrm{DP}=1,20)$ e, quando o alvo é masculino elas, também, concordam mais com a atribuição $(\mathrm{M}=4,08, \mathrm{DP}=1,02)$ que eles $(\mathrm{M}=3,78$; $\mathrm{DP}=1,12)$. Pode-se dizer que as adolescentes apresentam uma tendência maior em considerar ambos os grupos como autoritários. Contudo, elas consideram os meninos bem mais autoritários que as mulheres. Eles, apesar de também concordarem que ambos os alvos são autoritários, têm tendência em perceber os membros do próprio grupo como sendo um pouco mais autoritários que os membros do grupo feminino. $\mathrm{O}$ resultado sugere que o fato de ser membro do grupo feminino levou as participantes a considerarem os meninos como mais autoritários, e o fato de ser membro do grupo masculino levou os participantes a percebê-los, também, como mais autoritários.

Na metapercepção, os dados indicam relevância da variável sexo nas atribuições $[\mathrm{F}(1,235)=6,897 ; \mathrm{p}=$ $0,009]$. A média das respostas delas $(\mathrm{M}=4,18$; $\mathrm{DP}=$ $1,23)$ demonstrou que elas tendem a acreditar que os meninos as percebem como muito mais autoritárias do que eles $(\mathrm{M}=3,76 ; \mathrm{DP}=1,24)$ acreditam serem vistos dessa forma por elas. Esses dados revelam uma correspondência entre autoestereótipo, heteroestereótipo e metapercepção para essa atribuição.

\section{F) Arrogante}

Analisando as atribuições do adjetivo arrogante para o alvo feminino, realizadas pelas adolescentes $(\mathrm{M}=$ $2,70, \mathrm{DP}=1,20)$ e pelos adolescentes $(\mathrm{M}=2,70, \mathrm{DP}=$ $1,20)$ em comparação com as atribuições delas $(\mathrm{M}=$ $3,70 ; \mathrm{DP}=1,14)$ e deles $(\mathrm{M}=3,18 ; \mathrm{DP}=1,15)$ para o alvo masculino, notamos que existe uma tendência dos grupos de participantes verem o grupo masculino como mais arrogante que o grupo feminino. Elas, contudo, são as que mais atribuem essa característica a eles. A percepção das meninas como arrogantes foi exatamente a mesma nas atribuições de ambos os grupos de participantes. Esses resultados demonstram que o sexo do avaliador parece ser um fator importante na atribuição deste adjetivo $[\mathrm{F}(1,235)=8,986 ; \mathrm{p}=0,003]$. 


\section{G) Farrista}

A análise da metapercepção indicou significância estatística para a variável sexo $[\mathrm{F}(1,235)=33,685 ; \mathrm{p}$ $=0,000]$. A média das respostas das adolescentes $(\mathrm{M}$ $=3,77 ; \mathrm{DP}=1,27)$ em comparação com a média das repostas dos adolescentes $(\mathrm{M}=4,58$; $\mathrm{DP}=0,82)$ indica que eles acreditam que são percebidos pelas meninas como farristas numa proporção bem mais acentuada do que elas acreditam serem percebidas, como tal, por eles.

\section{H) Inconsequente}

A análise da metapercepção indicou a variável sexo como relevante $[\mathrm{F}(1,235)=18,341 ; \mathrm{p}=0,000]$. A média das respostas das adolescentes $(\mathrm{M}=3,07$; $\mathrm{DP}=$ 1,36) em comparação à média das repostas dos adolescentes $(\mathrm{M}=3,78$; $\mathrm{DP}=1,19)$ indica que a metapercepção sobre serem inconsequentes é mais acentuada para os meninos que para as meninas. Esse resultado sugere que estes acreditam serem percebidos, por elas, como inconsequentes, numa proporção bem maior do que elas acreditam serem percebidas, como inconsequentes, por eles.

\section{DISCUSSÃO}

De acordo com os resultados obtidos, é possível identificar que as atribuições são significativamente mais intensas com relação ao grupo feminino que ao grupo masculino. Essa intensidade ocorre tanto no número de adjetivos que são utilizados para caracterizar o grupo quanto na média de concordância entre os participantes na atribuição dessas características. Esse resultado é similar ao que ocorreu em pesquisa anterior desenvolvida por Oliveira (2004). Esse dado parece sugerir uma facilidade em expressar e/ou atribuir características ao grupo feminino tanto por parte dos membros do próprio grupo quanto por parte dos membros do grupo externo. O mesmo não ocorre quando o alvo é o grupo masculino.

Com base nesse dado, seria pertinente questionar se esse tipo de manifestação se deve ao fato das meninas serem mais estereotipadas que os meninos. A resposta afirmativa a essa pergunta levaria a outras questões como: Por que as mulheres seriam mais estereotipadas que os homens? Por que seria mais fácil fazer atribuições ao grupo feminino que ao grupo masculino? Essa manifestação ocorreria somente entre os adolescentes ou seria possível identificá-la em outras faixas etárias (crianças, adultos, idosos)? Por que seria mais fácil ativar os estereótipos femininos que os masculinos? Essa pesquisa não apresenta dados que possam responder tais questões.

O segundo ponto a ser observado é que as adolescentes ainda possuem uma caracterização mais marcante através de atributos considerados expressivos, enquanto os adolescentes, membros do grupo masculino, possuem uma caracterização com base em atributos instrumentais. Essa tendência pode ser verificada através dos resultados da estatística descritiva, a partir da qual é observado que o grupo feminino obteve um número maior de atributos expressivos nos três níveis de análises realizados (auto e heteroestereótipos, e metapercepção). Mesmo assim, é importante registrar que o grupo feminino também obteve um número significativo de atributos instrumentais (uma média de 4,66 por nível) na sua caracterização. Os homens, por sua vez, foram caracterizados, na sua maioria, por atributos instrumentais (somente o atributo companheiro, característica considerada expressiva, aparece na caracterização do grupo masculino). Esse resultado indica uma relativa manutenção do padrão estereotipado e apresenta-se em consonância com pesquisas, como a realizada por D' Amorim (1997), que apontam as mulheres como sendo identificadas principalmente por atributos expressivos ou coletivistas e os homens por atributos instrumentais ou individualistas. É interessante notar, contudo, que a visão sobre as mulheres permite uma utilização maior daqueles adjetivos considerados mais característicos do grupo masculino, enquanto que a visão sobre os homens parece evitar as características identificadas como tradicionalmente femininas. Por que isso ocorreria? Essa diferença poderia ser respondida pelas mudanças nas estruturas sociais, nas quais a mulher tem participado mais ativamente da vida pública, tem assumido responsabilidades antes consideradas masculinas (como a manutenção financeira da família, o investimento na carreira profissional) e tem atuado em áreas profissionais mais diversificadas? E o homem? Ele, também, não tem assumido funções que anteriormente eram vistas como características do grupo feminino, como a participação mais ativa no cuidado da casa e dos filhos? E, por que, então, os adolescentes preferem admitir que os meninos estão sendo mais companheiros porém, não são muito sensíveis, delicados e românticos? Seria o adjetivo companheiro visto como uma expressão dessas mudanças sociais, não implicando, necessariamente, que eles se tornem mais sensíveis e delicados?

A partir da análise inferencial, também é possível fazer algumas observações. No caso dos adjetivos bonito e vaidoso, cabe notar que a dificuldade do homem em admitir que pode achar outro homem bonito 
permanece na concepção dos adolescentes. O mesmo não ocorre quando os meninos se avaliam como vaidosos, assumindo que essa característica pode ser tanto feminina quanto masculina. Os participantes da escola confessional foram os que mais manifestaram concordância com a atribuição desses dois adjetivos. No caso dos adjetivos convencido e metido, que são considerados negativos, ambos são atribuídos mais ao grupo externo que ao próprio grupo, corroborando a noção de que são valorizados mais atributos negativos na caracterização dos membros do grupo externo. Nota-se, mais uma vez, a tendência de níveis mais altos de concordância com essa atribuição entre os alunos do colégio confessional e a tendência das meninas serem as que mais esperam ser vistas como bonitas, vaidosas, metidas e convencidas que os meninos.

Quando os resultados sobre os adjetivos que compõem a dimensão expressiva são analisados, é observada uma tendência dos alunos da escola confessional utilizarem, de forma mais intensa, esses atributos e, entre esses alunos, foram as meninas as que utilizaram tais atributos de maneira mais marcante. Nos resultados sobre as atribuições dos adjetivos organizado e responsável, o sexo apareceu como uma variável com diferenças significativas nas atribuições. Essas características foram consideradas mais femininas que masculinas. Mesmo assim, ainda é possível identificar um favorecimento sutil do próprio grupo nestas atribuições, mais com relação ao adjetivo responsável que com relação ao adjetivo organizado. As meninas foram consideradas, por elas mesmas, mais responsáveis e organizadas que os meninos. Eles, por sua vez, percebem-se como responsáveis, porém veem as meninas como mais responsáveis que eles. Além disso, foi possível observar que a expectativa das meninas sobre a forma pela qual são percebidas pelos membros do grupo externo, em relação a estes atributos, é muito maior que a dos meninos. No caso do atributo romântico, alunas da escola leiga são as que mais acreditam serem percebidas como românticas pelo grupo masculino. Os meninos, alunos da mesma escola, são os que menos acreditam que são vistos como românticos pelas meninas.

As análises sobre os traços instrumentais demonstram, mais uma vez, que os alunos da escola confessional foram os que mais tenderam a concordar com a atribuição das características, como é observado no caso dos adjetivos estudioso, inteligente e persistente. Um fato interessante ocorre com relação ao atributo autoritário. Apesar de ser tido como um traço instrumental, nesta pesquisa os participantes tenderam a considerá-lo como característico tanto das meninas quanto dos meninos. Por outro lado, esse adjetivo não é considerado culturalmente um atributo positivo e, sendo assim, seria de se esperar que os grupos evitassem atribuí-lo aos membros do grupo a que pertencem. Isso não acorreu. As meninas consideram como autoritários tanto os membros do seu grupo quanto os membros do grupo externo, apesar de atribuírem mais essa característica aos meninos. Estes, por sua vez, se percebem como mais autoritários que as meninas. Diante desses resultados seria possível perguntar: Qual a percepção dos adolescentes sobre esse atributo? Será que eles o interpretam como algo negativo de fato? Ou, será que admitem esse traço como característico dos membros dos seus grupos, mesmo sendo ele considerado algo negativo? Também, é possível questionar se o fato dos membros do grupo masculino serem percebidos como mais autoritários, tanto por elas quanto por eles próprios, seria fruto de uma educação, de uma formação sociocultural que favoreceria, ou mesmo valorizaria, o comportamento de dominação dos homens. Interessante notar sobre esse atributo que, apesar dos meninos se considerarem mais autoritários, as mulheres acreditam mais que são percebidas como autoritárias por eles.

$\mathrm{Na}$ atribuição do adjetivo arrogante, homens e mulheres percebem o grupo feminino como menos arrogante que o grupo masculino. O mesmo não ocorre na avaliação dos homens, que são vistos, pelas mulheres, como bem mais arrogantes. Isso reforça o resultado anterior sobre o atributo autoritário. Os homens parecem ser vistos como um grupo que tende a impor com mais frequência suas vontades, interesses e opiniões sobre a dos outros. Por fim, mesmo que homens e mulheres sejam vistos e se vejam como farristas e inconsequentes, são os homens que esperam mais que elas os vejam dessa forma. Esses resultados demonstraram que existe de fato uma tendência em manter o padrão de traços instrumentais como uma característica masculina, mesmo que, na maioria dos casos, esses sejam reconhecidos, também, como características femininas.

Com relação aos atributos bonito, vaidoso, vulgar, convencido e metido, as meninas receberam esses atributos de maneira mais intensa; os meninos ainda preferem evitar atribuir o adjetivo bonito a outros homens, mas se percebem como vaidosos. $\mathrm{O}$ adjetivo vulgar não foi muito valorizado nas atribuições dos adolescentes, tanto meninas quanto meninos. As meninas foram as que mais evitaram esse atributo, principalmente quando avaliaram os membros do seu grupo. 
No caso dos adjetivos convencido e metido, considerados atributos negativos, a tendência foi de esses atributos serem menos valorizados na caracterização dos membros do próprio grupo que para os membros do grupo externo.

Por fim, foi possível verificar que as atribuições mais intensas ocorreram entre os alunos, de ambos os sexos, do colégio confessional. Essa ocorrência poderia sugerir que existe uma tendência desses alunos estarem mais sujeitos a ativar e aplicar os estereótipos. O que levaria esse grupo a estar mais sujeito a estereotipar? Essa é uma questão que necessita de mais pesquisas. Contudo, seria possível supor que provavelmente esses adolescentes estariam submetidos a uma educação tradicional, o que, talvez, os levaria a manter uma visão pautada em estereótipos tradicionalmente entendidos como característicos de grupos de gênero.

\section{REFERÊNCIAS}

Allport, G. (1988). The nature of prejudice. Cambrige, MA: Perseus Books.

Costa, A. T., Dirreti, L., Nunes, F. G., \& cols. (2002). Relacionamentos amorosos na adolescência: Diferenças de gênero. Em Sociedade Brasileira de Psicologia (Org.), Anais da XXXII Reunião Anual de Psicologia (p. 201). Florianópolis: SBP.

D’Amorim, M. A. (1997). Estereótipos de gênero e atitudes acerca da sexualidade em estudos sobre jovens brasileiros. Temas em Psicologia, 3, 121-133.

Desouza, E., Baldwin, J. R., \& Rosa, F. H. (2000). A construção dos papéis sexuais femininos. Psicologia: Reflexão e Crítica,
13, 485-496. Retirado em 20 de março de 2005, da base de dados SciELO.

Fonseca, V. N. (2002). Sexualidade nos novos tempos: O discurso de mulheres adolescentes sobre sexo e relacionamentos. Em Sociedade Brasileira de Psicologia (Org.), Anais da XXXII Reunião Anual de Psicologia (p. 271). Florianópolis: SBP.

Greenwald, A. G., Banaji, M. R., Rudman, L. A., Fernham, S. D., Nosek, B. A., \& Mellot, D. S. (2002). A unified theory of implicit attitudes, stereotypes, self-esteem, and self-concept. Psychological Review, 109, 3-25.

Hertel, G., \& Kerr, N. L. (2001). Primming in-group favoritism: The impact of normative scripts in the minimal group Paradigm. Journal of Experimental Social Psychology, 37, 316324.

Krüger, H. (1986). Introdução à psicologia social. São Paulo: EPU.

Lima, M. E. O., \& Pereira, M. E. (Orgs). (2004). Estereótipos, preconceitos e discriminação: Perspectivas teóricas e metodológicas. Salvador: EDUFBA.

Oliveira, L. L. (2004). Estereótipos de gênero em adolescentes. Dissertação de Mestrado não-publicada. Universidade do Estado do Rio de Janeiro, Rio de Janeiro.

Pereira, M.(2002). Psicologia social dos estereótipos. São Paulo: EPU.

Tajfel, H. (1982). Grupos humanos e categorias sociais. Lisboa: Livros Horizonte.

\section{Sobre as autoras:}

Recebido: 02/08/2007

Última revisão: $30 / 04 / 2010$ Aceite final: $20 / 05 / 2010$

Luciana Lopes de Oliveira: Psicóloga e Bacharel em Psicologia pela Universidade Federal de Juiz de Fora (UFJF), Mestra em Psicologia Social pela Universidade do Estado do Rio de Janeiro (UERJ), Professora da Universidade Presidente Antônio Carlos (UNIPAC Barbacena/MG).

Dalva Cristina Aparecida de Jesus: Graduanda do Curso de Psicologia da Universidade Presidente Antônio Carlos (UNIPAC - Barbacena/MG).

Maria Aparecida de Lima Arruda: Graduanda do Curso de Psicologia da Universidade Presidente Antônio Carlos (UNIPAC - Barbacena/MG).

Maria Celestina da Cunha: Graduanda do Curso de Psicologia da Universidade Presidente Antônio Carlos (UNIPAC - Barbacena/MG).

Raquel Mara Araújo: Graduanda do Curso de Psicologia da Universidade Presidente Antônio Carlos (UNIPAC - Barbacena/MG).

Endereço para correspondência: Luciana Lopes de Oliveira. Rua Ernesto Pancini, 70 - São Judas Tadeu - 36087-570 Juiz de Fora/MG. Endereço eletrônico: lulopes.oli@gmail.com / luciana.lopes@ifsudestemg.edu.br. 